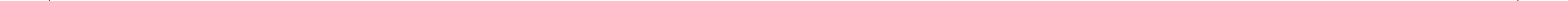




\section{Competences in music}

\section{Abstract:}

This document is intended, from the perspective of the study of bass or stringed instruments of the violin family, although nothing is ruled out other instruments to reflect that allows an approach to the problem that you can live a music educator who manages one of these instruments and also, make a proper problem definition and formulation of appropriate solutions in order to understand the environment surrounding her performance.

Had been raised in earlier document called "Using a bowed string instrument in a music class", a teaching model that offers tools that order, now tries to approach to a teaching model called Competence, which can inferred as a derivative of constructivism and on which, and although it is somewhat uncomfortable, it is necessary to note that their speech can easily be associated with the discourse of labor productivity in the enterprise.

It is expected that this model offers opportunities to better understand the environment in which a professional musical education should make his events, mediated by new technologies and their effect on production, distribution, dissemination and reception of music, as well as the phenomenon of commercialization used by industry and that as a result of this and the impact that this phenomenon involves the construction of new paradigms, values and concepts that are imposed as building models.

\section{Key words:}

String instrument of the violin family, musical competences, musical context, musical industry.

\section{As Competencias Em Musica}

\section{Resumo:}

Este documento deseja, desde perspectiva do estudo do contrabaixo o qualquer outro instrumento de corda da família do violino, embora não se descartem os outros instrumentos; fazer uma reflexão que permita ficar mais perto a problemática que possa viver um professor de musica que interpreta um destes instrumentos e assim mesmo, fazer uma definição dos problemas e a formulação de soluções com o fim de compreender o entorno que rodeia seu ato.

Já se tinha formulado um documento prévio nomeado "uso de um instrumento de cordas em uma aula de musica" Uma proposta didática, que fornece ferramentas de essa ordem, agora se tenta ficar mais perto de um modelo de ensino nomeado como "competências", o qual se pode deduzir como um derivado do construtivismo e sobre o qual, e embora seja um poço incomodo, é preciso dizer que seu discurso pode-se associar facilmente com o discurso de produção laboral numa empresa.

Aguarda-se que este modelo ofereça possibilidades de compreender melhor o meio em que um profissional de educação musical deve fazer de seu acontecer, imerso nas novas tecnologias e seu efeito na produção, distribuição, difusão e recepção da musica, também o fenômeno da mercantilização utilizada pela indústria e daquele como produto desta e o impacto que este fenômeno leva na construção de novos paradigmas, valores e conceitos que se impõem como modelos de criação.

\section{Palavras Chave:}

Instrumento de cordas da família do violino, Competências em musica, contexto em musica, indústria de musica.

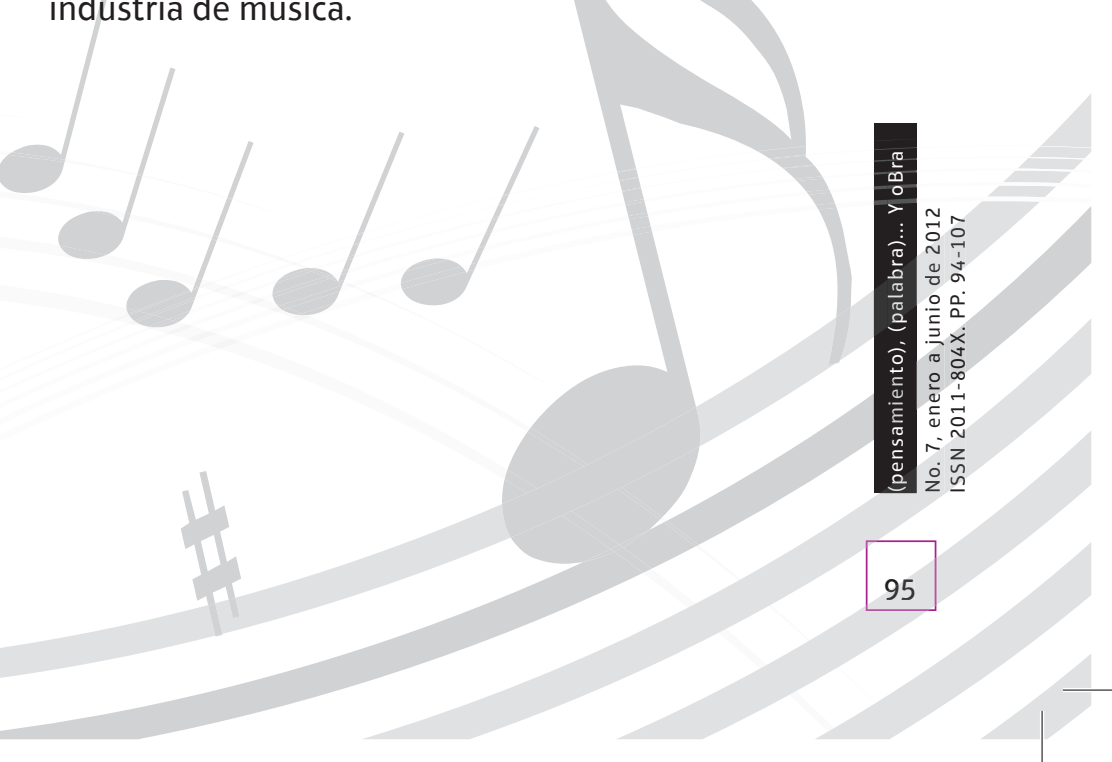




\section{Introducción}

El entorno determina el marco de acción para la vida de cualquier persona. Entenderlo se plantea como la base sobre la cual ha de construirse la cadena que va del entendimiento de ese entorno, a la construcción autónoma de criterios y elementos de juicio y análisis para llegar al accionar autónomo y responsable. La correcta definición de los problemas y la formulación de soluciones adecuadas conllevan una comprensión y análisis del contexto local y global.

\section{Crisis de legitimación}

Elementos como las nuevas tecnologías y la mercantilización de la música, han dejado a los músicos y a los educadores de la música, ya sea por incapacidad para actualizarse o por desidia, en una crisis de legitimación en la que no es claro cuáles son los beneficios que su práctica aporta a la sociedad.

A esa crisis de legitimación hay que agregar la ambigüedad; en el mejor de los casos porque es generalizada la ignorancia alrededor del concepto de estética. El término se emplea de manera muy amplia y eso lo hace impreciso, pues allí se incluye cualquier cosa y aun todo aquello que no es ni cognición ni acción. No se puede desconocer la dificultad para formular una definición y una teoría sobre estética: el término ha comprendido experiencias muy diversas. Dentro de él están: el arte, la creatividad, la forma, la belleza y también la mimesis, sin desconocer la misma experiencia estética que no debe entenderse como la estética en sí misma. 
Ya Pitágoras en su reflexión sobre belleza nos dice: "La vida es como una experiencia atlética; algunos son luchadores, otros vencedores ambulantes, pero los mejores aparecen como espectadores" (citado por Tatarkiewicz, 1987, p. 359). "Schopenhauer define la estética, sencillamente, como contemplación" (citado por Tatarkiewicz, 1987, p. 362): actitud asumida por el espectador concentrándose solamente en lo que tiene ante él. La importancia de esta teoría es que genera otras tantas teorías de gran relevancia para el medio educativo y en general para la ciencia. Se pueden nombrar como teorías generadas por la teoría de la contemplación: la Teoría del aislamiento, que propone el aislamiento del objeto y separación del sujeto como primera condición para la experiencia estética. Lo anterior supone aplicabilidad no solo para alcanzar la experiencia estética sino también en la vida práctica; Teoría de la distancia psíquica, que se resume en que la experiencia estética supone una concentración sobre el objeto generador de la experiencia y pensar en sí mismo. Otra importantísima teoría es la Psicología de la Gestal, que supone aportes a la ciencia después de encontrar las leyes que dominan la percepción. Es pertinente anotar que la teoría de la Gestal no se ocupó en un principio de la estética, pero al hacerlo descubre que la experiencia estética es posible si la mente, los sentidos y la memoria captan la totalidad del objeto. Debe agregarse a este listado de teorías resultantes de la Teoría de la contemplación dada por Schopenhauer, la Teoría de la euforia, que asume la experiencia estética como algo puramente emocional en el que se rechaza el elemento intelectual; es así como se nos revela el aspecto intuitivo. Se concluye entonces que para la Teoría de la euforia, la inclusión del intelecto no permite la participación de ninguna intuición ni belleza y, por supuesto, ninguna experiencia estética (Tatarkiewicz, 1987).

Alexander Baumgarten (Tatarkiewicz, 1987, p. 362), creador del término estética, la define como "ciencia del conocimiento sensitivo", que genera la tercera crítica de Emanuel Kant: el libre juego de las facultades del conocimiento que conduce las reflexiones sobre la estética hacia una disciplina filosófica cuyos presupuestos modifican las relaciones entre los objetos y el conocimiento que tenemos de ellos. (Tatarkiewicz, 1987).

La estética como disciplina filosófica supone, por decirlo de alguna manera, captar la luz de lo bello no en el objeto visto sino en sí misma. El empeño de Kant no está en el conocimiento de los objetos sino en el conocimiento reflejo de lo que puede haber a priori, es decir, el conocimiento reflejado desde el objeto al que se agregan formas y categorías que el intelecto del individuo aporta como formas a priori y que ordenan las impresiones dadas por la experiencia. (Labrada, 1983).

Así es posible separar los contenidos conceptuales de actividad cognoscitiva, y es la dirección que toma la conciencia en el juicio de la belleza donde se objetiva la forma pura del conocimiento. Esa objetivación no es de orden cognoscitivo sino sentimental; se trata de un gozo intelectual, de tratar de sentir las condiciones de inteligibilidad máximas, de libertad total en armonía con las facultades cognoscitivas interactuando entre sí. De esta manera Emanuel Kant desarrolla la posibilidad del juicio estético, planteado desde Baumgarten en el ámbito del conocimiento sensitivo en el terreno de unas condiciones de conocimiento intelectual.

Dando continuidad al tema de la ambigüedad o ignorancia de los músicos sobre el concepto de estética, puede pensarse como causa de la mencionada ignorancia el que no exista, en el currículo de cualquier institución universitaria, un espacio para estudiar la estética, quedando ausente de la formación del músico profesional.

Se habla de ambigüedad del concepto de estética no solamente por la amplitud del mismo como se anotaba antes, sino porque ésta se asocia generalmente con "sensación placentera" (Williams, 1983, p. 31-33), y se puede hablar desde allí de "estética del deporte" o "cirugía estética" (Regelski, 2004. p. 24

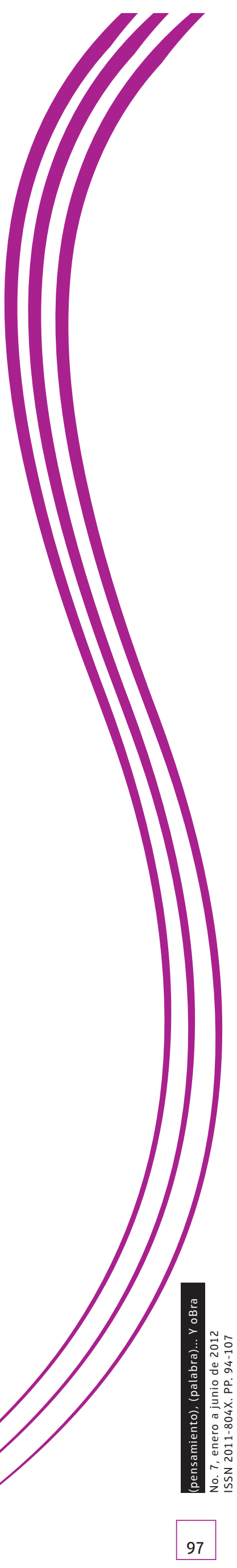


Pero lo más grave es que es eso lo que entienden los músicos y los educadores de música por "Educación estética". Además, a la crisis de legitimación se puede aunar lo que el autor Thomas A. Regelski denomina como la metodolatría, para referirse al "tecnicismo de la enseñanza" o "la pedagogía de recetas" (Regelski, 2004. p. 24-30), que se hace manifiesta en la utilización de un libro que contiene estudios de desarrollo de habilidades técnicas para tocar el instrumento; libro generalmente denominado método, que se convierte en el centro de planificación del profesor, cuando lo pertinente es seleccionar diferente literatura musical de todos los géneros y estilos y de todos los períodos de la historia , incluida por supuesto, la que se encuentra dentro del método, que pueda tener importancia para el aprendizaje de lo técnico y lo discursivo musical a lo largo de toda la vida.

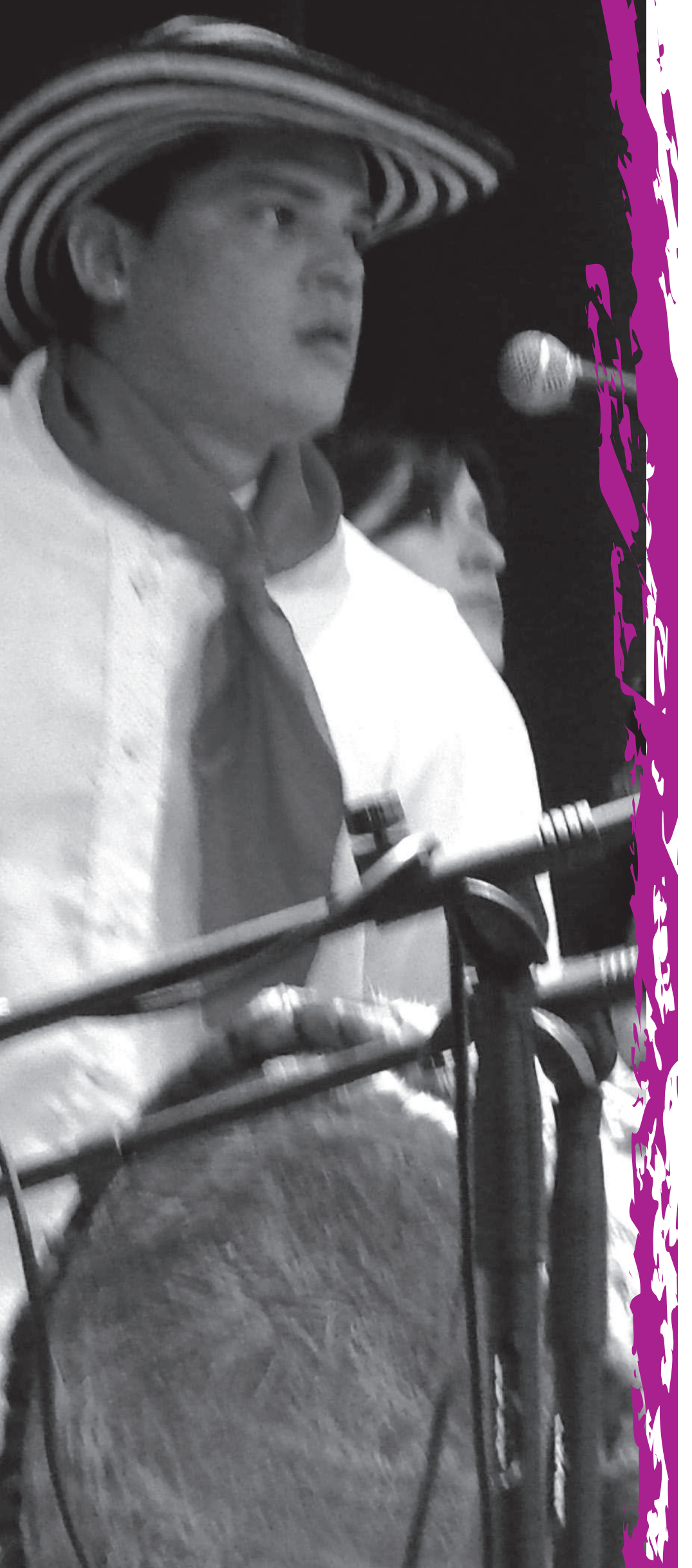




\section{Lo que se enseña en música}

También se puede mencionar que generalmente la clase de música está centrada en la enseñanza de sus elementos (no puede faltar la historia y lo que se denomina teoría, que no es teoría) y en el caso de una clase de instrumento, saber música se reduce a desarrollar habilidades de orden motriz (técnica). Para nada se tienen en cuenta los elementos discursivos como forma de dotar de significado las prácticas musicales y cuál es el lugar que le corresponde al receptor de la obra de arte como interlocutor dotado de capacidad interpretativa. Es que las cosas para ser inteligibles, deben existir dentro de un marco de significado dado por sus intérpretes en términos de pragmática, dependiendo del contexto en que se sitúen. Una piedra puede ser un ladrillo útil en la construcción de una casa, un proyectil, parte de un hallazgo arqueológico, etc., todo depende del discurso y las circunstancias que le den significado o ser al objeto. En el caso concreto de la música puede tratarse de un evento comunicativo, una forma de interacción social mediante la cual se hace manifestación de emociones o sentimientos, en fin, depende de los usos que cada grupo social y cada cultura haga de la música.

\section{La música también es un sistema de símbolos}

El ser humano cuenta con un variado repertorio de herramientas simbólicas que median en sus distintos modos de actuar, que están enmarcados dentro de una perspectiva semiótica que posibilita construir la realidad e interactuar con sus congéneres, en situaciones y con propósitos diferentes. De ese repertorio hace parte fundamental el lenguaje, quizá por su preeminencia en la construcción intelectual en el universo académico avalado por el acontecer histórico hasta ahora presente en nuestras visiones de mundo; pero no es la única herramienta con la cual se construye sentido sobre el mundo y sobre nosotros mismos, nuestras acciones y decisiones, nuestra forma de pensar y de aprender, nuestros actos intelectuales. Cada una de las formas de representación que han creado formas sígnicas, facilitan la comunicación, los diferentes sistemas semióticos que afectan de distinta manera los sentidos. Entonces puede pensarse que los lenguajes no verbales (se habla dentro de los lenguajes no verbales por ejemplo de la Proxémica, la Cronética, la Paralingüística, la Quinésica, etc.), la Literatura, la Música, y todas las demás formas de arte, mutatis mutandis, los mitos, los relatos, las metáforas, etc., se constituyen en herramientas simbólicas a ser desarrolladas mediante la formación en competencias.

\section{Las competencias}

Se habla de competencia para referirse a "la capacidad o disposición que posee una persona para dar solución a problemas reales y para producir nuevo conocimiento".

Cuando se habla de capacidad o disposición, se habla de aptitud, es decir, se habla de ser apto para alcanzar un determinado fin. Pero es necesario precisar la aptitud como algo innato que aparece en cualquier momento en la niñez y la adolescencia e incluso en etapas posteriores, aptitud que al ser estimulada, se desarrollará. Ahora bien, es posible que no exista esa aptitud, y en tal caso se puede desarrollar una capacidad (habilidad desarrollada). Así, los desempeños seguramente no van a ser tan expeditos y fluidos como cuando hay aptitud, pero sí es posible, aun en los casos de deficiencias o enfermedades cerebrales, alcanzar algún grado de competencia. Un ejemplo conocido puede ser la aptitud para la música en la que el individuo nace con la capacidad de poder discriminar las propiedades de los sonidos, (altura, timbre, intensidad y duración). A esto coloquialmente se le llama "tener oído"; pero además de esto puede memorizar y reproducir con facilidad las propiedades con el ritmo que contengan. No "tener oído", es decir, no tener aptitud para la música, no impide poder desarrollar algún nivel de desempeño. 
sical para solucionar problemas reales de y con la música como: decodificar o codificar rítmicamente, hacer discriminación interválica, etc., y, dentro de lo mismo, producir nuevo conocimiento, disposición que debe ser estimulada y desarrollada por el sistema de enseñanza basado en competencias. Pero también es posible desarrollar capacidades con esos fines aunque no existan aptitudes que lo faciliten.

Entonces el sistema educativo debe trabajar sobre tres elementos complementarios: sobre el individuo para desarrollar sus habilidades, destrezas y técnicas; sobre el área de conocimiento o disciplinar y sobre el contexto que surte de usos y situaciones reales problemáticas.

También se puede colegir de estas afirmaciones que, en tanto se nace con la aptitud, las competencias no son el resultado de un aprendizaje sino que éstas se desarrollan en las personas a consecuencia del actuar, del hacer, y se manifiesta en un saber hacer o un saber cómo hacer; saber que está implícito en la actuación misma y no es de tan fácil acceso a la conciencia, por lo queresulta difícil dar cuenta de él.
"Cada competencia es específica de un dominio y se aplica a una actividad particular, ella no genera otras competencias que no sean de su misma naturaleza, lo que significa que cada competencia debe desarrollarse por separado de acuerdo a las exigencias del entorno" (Ospina, 2005, p. 5). Esta afirmación responde la inquietud muy válida planteada en el artículo "Las competencias lingüística, ideológica y comunicativa, a propósito de la evaluación masiva en Colombia", cuando se hace la pregunta reflexionando sobre la proliferación de competencias: "¿Tiene esto algún límite? ¿Se pueden agregar competencias ad libitum?" (Bustamante, 2003, p. 3). La respuesta sería: no ad libitum pero si cuantas la actuación en contexto requiera.

La competencia es la capacidad de una persona para lograr un resultado, según criterios preestablecidos en un ámbito específico. El mejoramiento depende en gran medida de ese ámbito en donde el desempeño está determinado por las condiciones de respuesta del ámbito. He ahí la importancia de generar espacios donde se pueda hacer música, léase orquestas, bandas, concursos, festivales, etc.

Es muy normal, desde la educación, preparar y garantizar la capacidad potencial para realizar tareas o funciones que suponen circunstancias y contextos ideales y homogéneos. Hoy en día se pretende que la educación en competencias prepare para realizar las tareas reales, aunque sus resultados tendrán que ser garantizados por otros mecanismos de gestión en la institución.

A la formación deben agregarse, de una parte, la organización de situaciones de trabajo como ámbito de aplicación de esa formación, a partir de unos recursos personales como el conocimiento y el saber hacer aunados a las cualidades y la experiencia, y de otra parte, unos recursos externos como herramientas, instrumentos, bancos de datos, bibliotecas, asociación a redes de profesionales, etc., de tal manera que se haga uso de conocimientos combinados o combinatorios para realizar varias actividades, tantas y tales como sea necesario para sortear las dificultades y solucionar los problemas en la realización de los proyectos puestos a responsabilidad.

Lo importante no es la posesión de unos conocimientos sino el uso que se haga de ellos. Esto parece ser muy claro y no tiene mayor discusión, los conocimientos no están para ser poseídos, tenidos en algún archivo, están para su uso en la satisfacción de necesidades que el entorno nos impone. Pero vale la pena preguntarse: ¿el uso que se hace de los conocimientos sí está utilizando esos conocimientos en su totalidad? Es 
decir ¿las personas competentes en un instrumento musical sí están usando todos los conocimientos que tienen? ¿Los usos generan conocimiento o será posible que los conocimientos generen usos diferentes? ¿Cuál debe ser la postura que se debe adoptar cuando lo que se usa es muy poco frente a lo que se sabe? La actuación permite conocer la competencia y así mismo los conocimientos implicados. Organizar situaciones de trabajo arroja desarrollo de competencias que van a permitir actuaciones fluidas $y$, por decirlo de alguna manera, eficientes y eficaces, pero la actuación, a no ser que se haga con fines investigativos o algo relacionado, va a ser gobernada por los usos y las costumbres de los paradigmas o visiones de mundo imperantes, pero los usos no hacen uso -valga la redundancia- de las propiedades físicas o de otra naturaleza como un juego, sino que les asigna funciones a estas propiedades y las utiliza con intencionalidades especificas y para satisfacer necesidades muy puntuales. En otras palabras, a los usos utilizados en el actuar les interesa satisfacer el paradigma y no la búsqueda del conocimiento, si no es que éste pueda resultar indispensable para la actuación.

Así las cosas, mal haría un sistema educativo, o lo que haga sus veces, en regirse excluyentemente por el paradigma de las competencias, pues en el desarrollo de éstas solamente se hace uso de lo que las visiones de mundo y el contexto requieren. Satisfacer las necesidades del mercado se convierte en imperativo y éste desarrollará competencias para sus necesidades, pero el trabajo con fines investigativos o el adentrarse en paradigmas diferentes a los impuestos por el contexto desarrolla competencias que superan los saberes y conocimientos requeridos por el mercado.
Es lo que sucede con instrumentos como el oboe o el fagote y otros que se utilizan en la orquesta sinfónica, que no son utilizados por la música del mercado y cuyo poco uso o desaparición se achaca a la moda. Particularmente, el contrabajo es usado por las nuevas músicas por su capacidad de producción de armónicos y su color de voz, y esto se satisface relativamente con poco estudio, no hay que estudiar diez o doce años para desempeñarse de manera eficiente como contrabajista en una de las nuevas propuestas. Eso sí, hay que ser docto en el lenguaje musical que se ejecuta y a eso hay que dedicar mucho tiempo, pero incluso si se maneja el lenguaje, no es necesario haber ido a la academia a estudiar contrabajo, cualquiera lo puede hacer.

Aquí resulta pertinente traer a colación un comentario que hizo el bandoneonista argentino Rodolfo Mederos (2010) en un panel sobre las músicas de Iberoamérica, realizado dentro del Tercer Congreso Iberoamericano de Cultura en la ciudad de Medellín, donde estableció tres categorías en las obras de los compositores: "La música de autor", en la que queda plasmado el pensamiento de un artista, circunstancia que le exige preparación, saber y conocimiento; "la música del pueblo", que según él tiene un origen popular y colectivo. Por último, señala "la música para el pueblo", que es creada en oficinas de mercadeo. Si se aceptara como válida la categorización de este músico, esta última categoría es la que resulta imponiéndose e imponiendo sus lógicas de acción y creación, y como habitante inmediato del contexto, desarrolla las competencias que requiere para sí, sin ocuparse, y no tiene por qué hacerlo, de nada más. Es al sistema educativo que corresponde dar otras miradas, tener en cuenta otras voces, otros discursos que puedan ser incorporados a lo contextual y a la formación por competencias.

No existe una sola manera de ser competente en música, como tampoco existe una sola competencia en música. Puede haber varias estrategias y conductas pertinentes y observables que permitan desempeñarse en diferentes escenarios, con un nivel apropiado en cada campo. Un perfil adecuado será determinante, de acuerdo a las necesidades y usos no solo de las instituciones y del entorno, sino de las solicitadas por la cultura y las visiones de mundo que se imponen en cada momento y lugar.

La competencia nace de la lingüística, con Noam Chomsky, y se extiende a otros campos del saber. No es posible hablar de competencias generales. Los conocimientos están claramente diferenciados en conocimientos declarativos y otros procedimentales, unos van dirigidos a un saber decir y los otros a un saber proceder. La competencia es un conocimiento inseparable de la actuación misma y de naturaleza distinta de las formas conceptuales y discursivas del conocimiento.

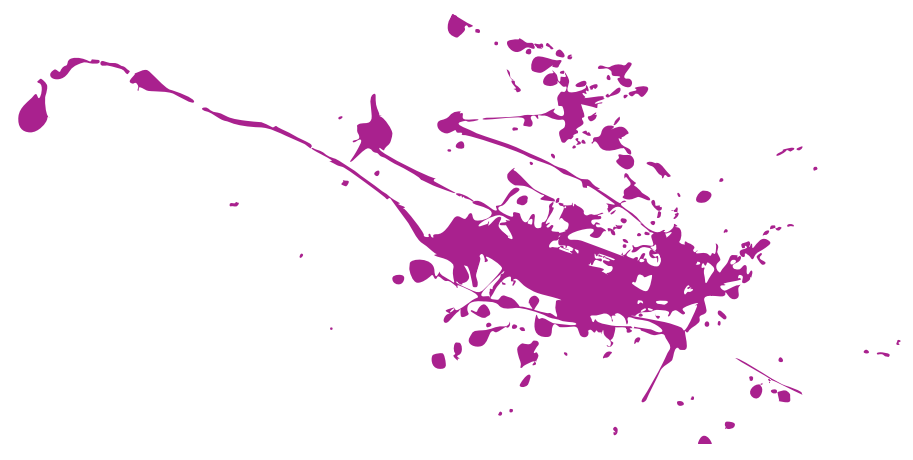


Fases para la implementación de la enseñanza basada en competencias

En esta parte se trata de abordar una estructura que a modo de pasos, permita implementar la enseñanza basada en competencias en la que se forme al estudiante para los usos que hace del contexto, de la música y del instrumento de cuerda que utiliza para el hacer musical, pero adoptando un pensamiento crítico que desde Adorno (citado por Sáenz del Castillo. 2007 p. 17), ya está recomendando la necesidad de mantener lo dado por el discurso formal, manifiesto especialmente en la partitura, pero descubriendo lo no dicho, lo no explicitado, aquello no definido pero que forma parte de la realidad, que está hablando de la interpretación, y que se hace manifiesto en las preocupaciones anotadas en párrafos anteriores en cuanto a regirse exclusivamente por el paradigma de las competencias, dado que una formación de esta índole no necesita estar mediada por el desarrollo de un plan formal de estudios en un programa académico, sino que basta con certificar la evidencias de esas competencias y estar en capacidad de demostrarlas por y frente a organismos acreditados y personas calificadas según el ámbito. En este sentido, la educación formal pierde su razón de ser, no solo en su intención de abandonar el paradigma positivista, sino como orientadora de intereses emancipadores que permitan al sujeto tener una vida libre, como es la aspiración desde las reflexiones que hace la Teoría Crítica de la Educación, una propuesta de enseñanza que intenta cuestionar y desafiar la dominación y las creencias y prácticas que la generan; así configura una teoría y práctica política y ética. No limita su acción a las aulas sino que pretende influir en la producción y construcción de significado en el ámbito de la semántica, pero muy principalmente pretende influir en la construcción de sentido como fin último de cualquier acto comunicativo. En esta tradición, el maestro trabaja para guiar a los estudiantes a cuestionar las teorías y las prácticas, animando a generar respuestas liberadoras tanto a nivel individual como colectivo, las cuales ocasionen cambios en sus condiciones de vida.

Es que asumir una posición crítica en la pedagogía significa enfrentar un mundo abierto de posibilidades diferentes donde se es más libre pero donde hay mayor responsabilidad y más inseguridad, entonces la reflexión y el diálogo se hacen importantes como procedimientos educativos. Asumir una posición crítica es superar las limitaciones tecnocráticas, es entender la educación como proceso que se extiende más allá del aula y hace que sus efectos se reflejen en la comunidad y en la sociedad en general.

La capacidad que tiene la escuela, por un lado, de reproducción de los valores dominantes, y por otro, de la transformación o mutación de éstos en tanto ámbito comunicativo y de creación de conocimientos, y a su vez la capacidad que tienen los estudiantes 


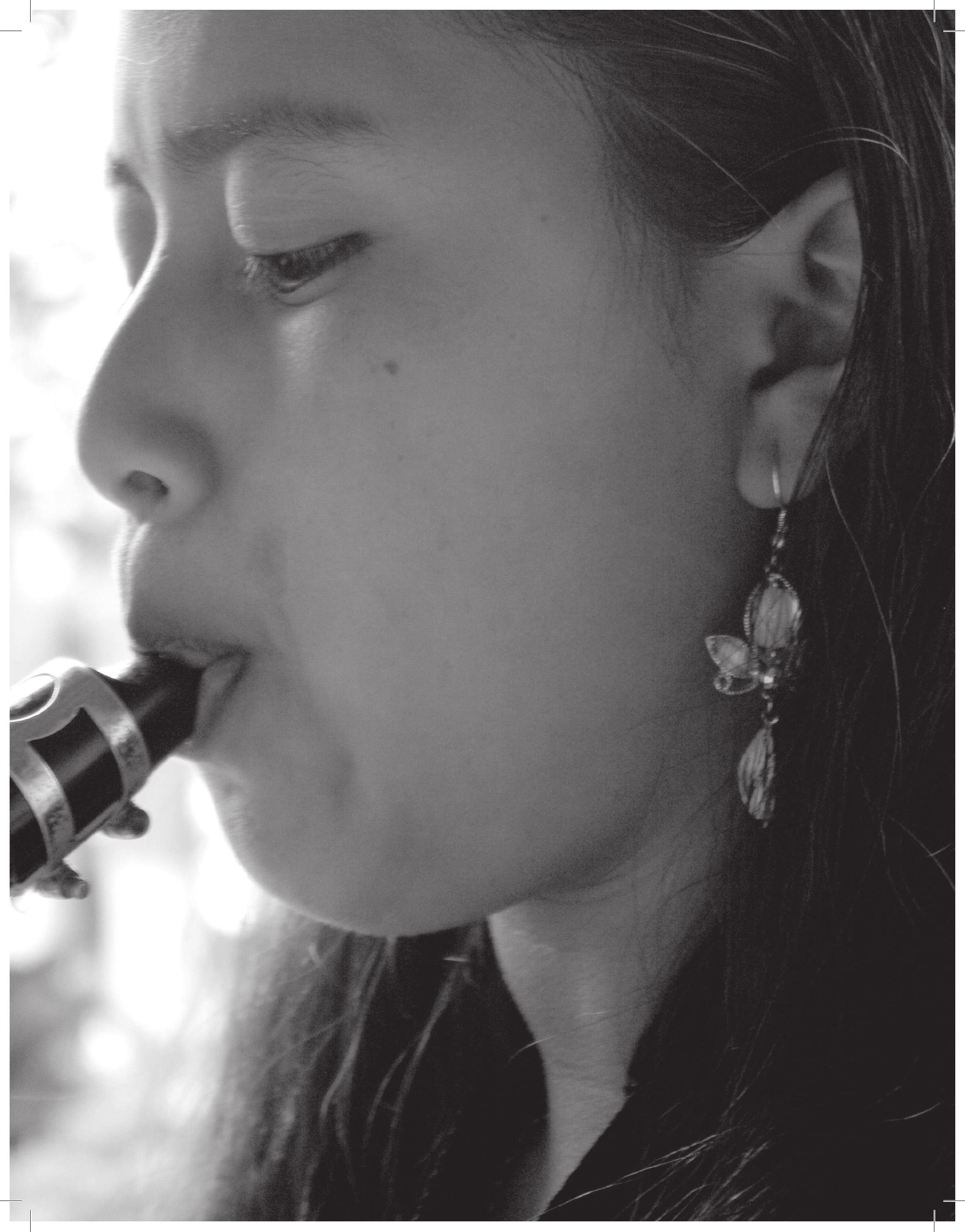


de resistir los intentos de homogenización cultural y de colonización del sistema educativo, pueden redundar en que el educador resulte estereotipado como un agitador político cuando lo que trata es de favorecer la reflexión y las relaciones simétricas en el diálogo, las posibilidades de reconocimiento y de reinvención, el humanismo crítico, el realismo esperanzado y principalmente los actos de conocimiento.

En Latinoamérica, la Educación Popular presenta elementos constitutivos que tienen analogías con los elementos planteados desde la Teoría Crítica:

Su postura ética es profundamente humana, es la ética de la vida que nos lleva como educadores a un permanente compromiso en pos de la transformación social desde nuestro espacio natural, la escuela, con su enorme capacidad, como ya se anotó, de reproducción de valores y a la vez de innovación $y$, por qué no, de mutación.

La Educación Popular entiende el conocimiento como elemento esencial del hecho educativo pero también como un fenómeno humano, social, histórico y contextual. Pretende construir (si es que es posible este término) sujetos liberados mediante la educación, por lo que no acepta desde ninguna tesis que el conocimiento pueda ser utilizado y entendido como instrumento de dominación o enajenación. Entonces, el conocimiento es construcción social permanente de los educandos en el acto personal y social de comprender y liberar. Así, el marco epistemológico de la Educación Popular es de carácter dialéctico y no positivista, lo que Freire denominaba "Educación Bancaria". El conocimiento es praxis permanente de los seres humanos sobre la realidad, entendiendo la realidad como fuente de 
un conocimiento que se genera socialmente en relación dialéctica entre el ser, el medio y la historia. La Educación Popular sostiene que la sensibilidad es el germen de todo conocimiento, pero ésta se transforma solo si alcanza la razón de actuar en un mundo objetivo pero que a la vez es susceptible de ser interpretado desde la subjetividad, desde las creencias, desde las ideologías, desde las posturas éticas y políticas.

En su propuesta metodológica, la Educación Popular propone un proceso de enseñanza-aprendizaje activo de carácter dialéctico donde el conocimiento es construido de forma colectiva, donde la teoría está al servicio de esta construcción y no sobre ella, la teoría al servicio de la práctica y no sometiéndola. La propuesta metodológica tiene como punto de partida la práctica social: parte de lo simple, de lo concreto, de lo personal y subjetivo, de lo más cercano para avanzar a lo abstracto, lo complejo, las categorías científicas para utilizar, entender, explicar, comprender e interpretar los fenómenos estudiados.

En esta propuesta el educador no pierde su rol de guía, de conductor; por el contrario, sigue siendo elemento sustantivo con gran responsabilidad en el desarrollo de la personalidad de los educandos, en el crecimiento de sus conocimientos y como actores activos y participativos del contexto y cultura en que están inmersos.

Su propuesta pedagógica está basada en la concepción de la educación como hecho democrático y democratizador, dentro del aula y más allá de ésta. Adhiere a la pedagogía del diálogo y la participación donde puede ofrecer su conocimiento porque está abierta al conocimiento de otros. Parte del nivel en que el educando se encuentra, de la manera como comprenden su medio, su realidad.

Su opción política se traduce en su reflexión y propuesta a favor de los marginados socialmente, de los oprimidos o excluidos. Pero no se queda solo en la reflexión, también actúa a favor, desde y en función de esos sectores y sus intereses.

\section{Fases del proceso}

El primer paso es establecer desde el entorno cultural, social, político y económico, las necesidades que hay de la disciplina en cuestión: la música. Hay que determinar cuáles son los beneficios que aporta ésta a la sociedad, para qué es útil y cómo se usa. Es un trabajo que debe darse desde la investigación en música y en educación musical, pues aunque ya se ha comenzado el proceso, todavía no se ha establecido con claridad si producir para satisfacer el mercado es establecer desde el entorno cultural, social, político y económico, las necesidades que hay en la disciplina.

Este primer paso arroja información sobre las áreas de conocimiento que son necesarias y así poder deducir el perfil requerido de acuerdo al rol que se va a desempeñar.

Un segundo paso es la elaboración de un currículo y un programa que satisfaga esas características.

El tercer paso va en el camino de acordar qué competencias deben ser desarrolladas, de acuerdo con los resultados de los pasos anteriores. Es importante señalar que se debe partir de las competencias básicas consignadas en el decreto 2566, y que son absolutamente pertinentes para el hacer musical y para el músico, competencias de las que se desprenden otras necesarias. Las competencias señaladas por el decreto en mención son:

Las competencias actitudinales que construirán el "SER" de la persona, las competencias cognitivas que construirán el "Saber" de ese individuo y las competencias aptitudinales que se ocuparán del "Saberhacer".

Deberá trabajarse en música sobre competencias científicas, competencias ciudadanas, competencia profesionales, etc. En todo caso y como quedó establecido en párrafos anteriores, tantas y tales competencias como la implementación del primer paso así lo arroje, competencias que se establecen desde el entorno cultural, social, político y económico, e informan sobre las necesidades que hay en la disciplina , trabajo que debe darse desde la investigación en música y en educación musical, esto es, el estudio del entorno. 


\section{Referencias}

Ayuste, A. (1997). Pedagogía Crítica y Modernidad. Cuadernos de Pedagogía No. 254, 80-85.

Bustamante, G. (2003). El Concepto de Competencia III. Un Caso de Recontextualización. Las "Competencias" en la educación colombiana. Bogotá, Colombia: Ed. Socolpe

Cepeda Dovala, J. M. (2004). Metodología de la Enseñanza Basada en Competencias. Extraído el 6 de Noviembre, 2009, de www. rieoei.org/deloslectores/709Cepeda.PDF

Chomsky, N. (1965). Aspectos de la Teoría de la Sintaxis. Barcelona, España: Ed. Gedisa

Díaz Barriga, A. (1997). Didáctica y Currículo. México: Ed. Paidós.

Labrada, M. A. (1983). Estética y Filosofía del Arte: Hacia una Delimitación Conceptual [Versión electrónica]. Anuario Filosófico, Vol. 16 N² Pág. 67-80

Ministerio de Educación Nacional. (2009). Las Competencias en la Educación Superior. Bogotá, Colombia.

Núñez Hurtado, C. (2009). Educación Popular: una mirada de conjunto. Guadalajara, México. Extraído el 27 de octubre, de www.educarecuador.ec

Ospina Duque, R. (2005). Las competencias, Nuevo Paradigma en la Educación Superior para el Siglo XXI. Colombia: Ed. Scripto Ltda.

Peña Borrero, L. B. (2008). La Competencia Oral y Escrita en la Educación Superior. Extraído el 29 de octubre. 2009. de www.mineducacion.gov.co

Regelski, T. A. (2004). La Música y la Educación Musical: Teoría y Práctica para "marcar una diferencia". Extraído el 29 de noviembre, 2008, de www.mayday-group.org

Rodríguez Rodríguez, R, (2008) Competencias en Evaluación. Extraído el 17 de noviembre, 2009 de www.unillanos.edu.co

Sáenz, A. Á. (2007). Teoría Crítica de la Educación. Extraído el 13 de junio. 2009 de www.educritica/idoneos.com

Tatarkiewicz, W. (1987). Historia de Seis Ideas. Madrid: Ed. Tecnos.

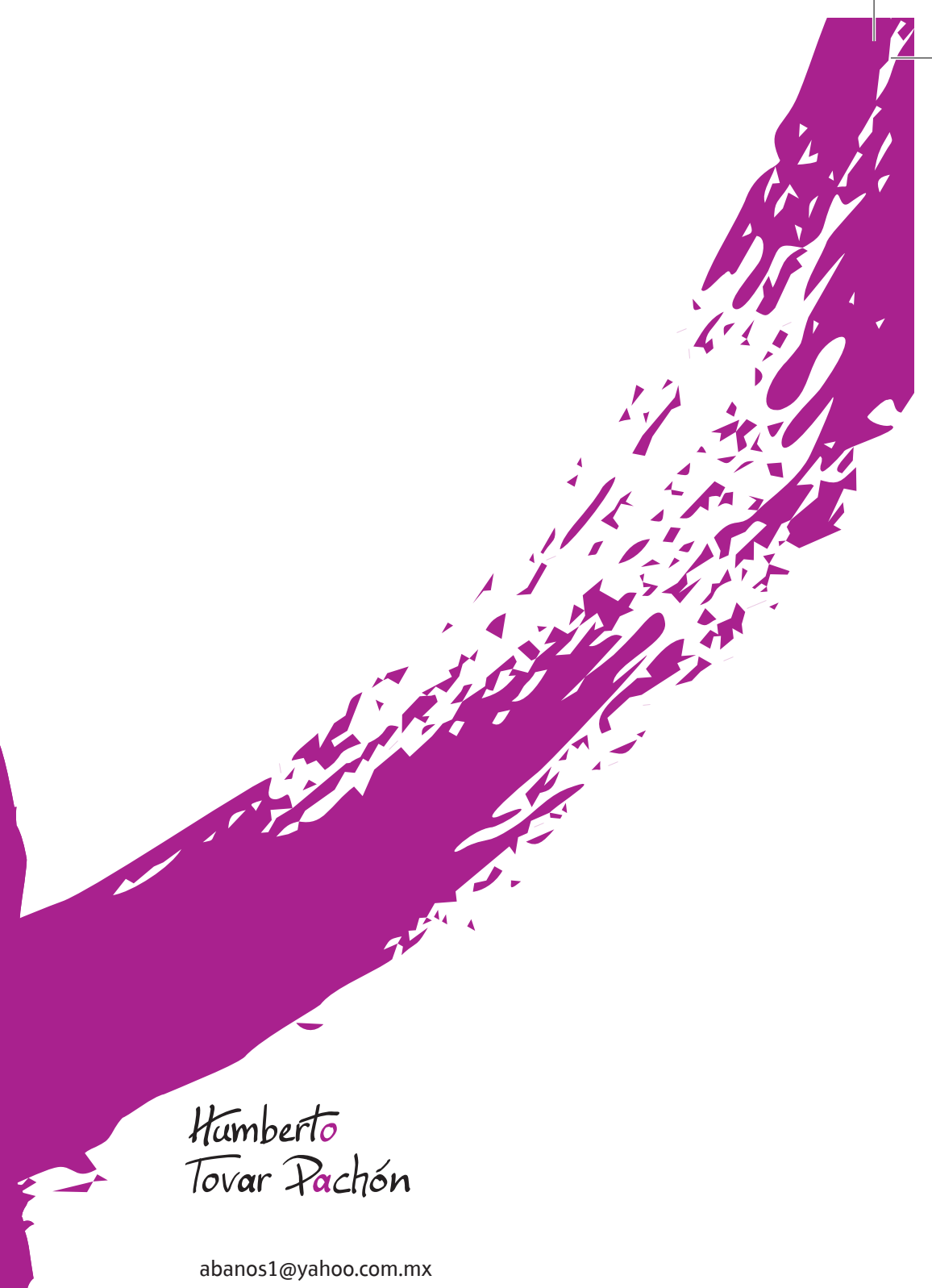

Músico egresado como contrabajista de la Universidad Nacional de Colombia, donde adelantó también estudios de Dirección. Especialización en Docencia del Español en la Universidad Pedagógica Nacional. Diplomado en Gestión y Gerencia de eventos musicales Universidad Sergio Arboleda. Músico de la desaparecida Orquesta Sinfónica de Colombia por más de diecisiete años, director y contrabajista de la orquesta de cámara ABANOS y del quinteto de cuerdas D'Cámara. Fundador y director de las orquestas de cuerdas de la Universidad Pedagógica Nacional y de la Universidad de Cundinamarca. Docente de la Facultad de Bellas Artes de la Universidad Pedagógica Nacional desde 1994, docente de la Universidad de Cundinamarca desde el año 2003.

Artículo recibido en diciembre de 2010 y aceptado en junio de 2011. 